\title{
Photovoltaic yield: correction method for the mismatch between the solar spectrum and the reference ASTMG AM1.5G spectrum
}

\author{
Thomas Mambrini ${ }^{1,2,3, a}$, Anne Migan Dubois ${ }^{2,3,4}$, Christophe Longeaud ${ }^{2,3}$, Jordi Badosa ${ }^{5}$, Martial Haeffelin ${ }^{5}$, \\ Laurent Prieur ${ }^{6}$, and Vincent Radivoniuk ${ }^{6}$ \\ 1 Université Paris-Sud 11, UMR 8507, LGEP, Bâtiment 301, 91405 Orsay Cedex, France \\ 2 SUPELEC, LGEP, UMR 8507, 3 rue Joliot-Curie, Plateau de Moulon, 91192 Gif-sur-Yvette Cedex, France \\ 3 CNRS, LGEP, UMR 8507, 11 rue Joliot-Curie, Plateau de Moulon, 91192 Gif-sur-Yvette Cedex, France \\ 4 Sorbonne Universités, UPMC Univ. Paris 06, UMR 8507, LGEP, 5 Place Jussieu, 75005 Paris Cedex, France \\ ${ }^{5}$ LMD, Institut Pierre-Simon Laplace, CNRS, Ecole Polytechnique, 91128 Palaiseau Cedex, France \\ ${ }^{6}$ SOLEÏS Technologie, 4 allée Jean-Paul Sartre, 77186 Noisiel, France
}

Received: 27 January 2014 / Received in final form: 22 October 2014 / Accepted: 3 December 2014 Published online: 6 February 2015

(C) Mambrini et al., published by EDP Sciences, 2015

\begin{abstract}
We propose a method for a spectral correction of the predicted PV yield and we show the importance of the spectral mismatch on the solar cell. Indeed, currently predicted PV yield are made considering solar irradiation, ambient temperature, incidence angle and partially (or not) the solar spectrum. However, the solar spectrum is not always the same. It varies depending on the site location, atmospheric conditions, time of the day... This may impact the photovoltaic solar cells differently according to their technology (crystalline Silicon, thin film, multi-junctions...) This paper presents a method for calculating the correction of the short-circuit current of a photovoltaic cell due to the mismatch of the solar spectrum with the reference ASTM AM1.5G spectrum, for a specific site, throughout the year, using monthly data of AERONET (AErosol RObotic NETwork established by NASA and CNRS) and the model SMARTS (simple model for atmospheric transmission of sunshine) developed by the NREL. We applied this correction method on the site of Palaiseau (France, $48.7^{\circ} \mathrm{N}, 2.2^{\circ} \mathrm{E}, 156 \mathrm{~m}$ ), close to our laboratory, just for comparison and the example of Blida (Algeria, $36^{\circ} \mathrm{N}, 2^{\circ} \mathrm{E}, 230 \mathrm{~m}$ ) is given for one year. This example illustrates the importance of this spectral correction to better estimate the photovoltaic yield. To be more precise, instead of modeling the solar spectral distribution, one can measure it with a spectro-radiometer, and then, derive the spectral mismatch correction. Some of our typical measurements are presented in this paper.
\end{abstract}

\section{Introduction}

Nowadays, the rated performance of photovoltaic (PV) modules is evaluated under standard test conditions (STC), that is to say at an irradiance of $1000 \mathrm{~W} \mathrm{~m}^{-2}$, a PV cell temperature of $25^{\circ} \mathrm{C}$ and a spectral energy distribution according to the reference spectrum AM1.5. This reference AM1.5 solar spectral distribution, adopted by the International Electrotechnical Commission (IEC), corresponds to a global irradiation (direct and diffuse) of incident sunlight on a flat surface facing the sun, tilted at $37^{\circ}$ to the horizontal, under precise atmospheric conditions $[1,2]$. In outdoor conditions, the solar spectral distribution varies continuously mainly due to (i) the path length through the atmosphere, named Air Mass $(A M)$,

\footnotetext{
a e-mail: thomas.mambrini@lgep.supelec.fr
}

(ii) the amounts of atmospheric water vapor $(w)$ and (ii) the aerosol volume (AOD). All those parameters depend on the considered site and the date.

The solar spectrum has a direct impact on the portion of sunlight absorbed by PV cells, more specifically, on the short-circuit current $\left(I_{s c}\right)$. The spectral photoresponse of a PV cell depends on the band gap energy, which is technology dependent. Thus, the effects of the solar spectral distribution should be different according to the PV technology considered [3,4]. Then, it may be useful to calculate the correction in $I_{s c}$ due to the spectral mismatch $(M)$ of the real solar spectrum compared to the reference solar spectrum for a given site and the considered PV cells. Currently, predictions of PV yield are made considering solar irradiation, ambient temperature, tilt and orientation of the panels. A few models take into account the effect of solar spectrum (e.g., PVsyst) [5] and when it is the case, not 
for all the PV technologies. Furthermore, the only parameter taken into account is $A M$. But the solar spectrum not only varies with $A M$ and can be very different according to the site (pollution for instance). We propose a method for a spectral correction of the predicted PV yield.

This paper proposes a method for estimating the correction of $I_{s c}$ due to the spectral mismatch, of any $\mathrm{PV}$ module knowing the spectral response of its unit cells. We explain how to reconstruct the solar spectrum with precise atmospheric data provided by AERONET (AErosol RObotic NETwork) [6], if available, or directly measure it with a spectro-radiometer.

The first part of this paper presents the tools used to study the solar spectrum and to recover the solar spectrum from atmospheric data. We also simulated the influence of atmospheric conditions on the solar spectrum through key parameters such as $A M, w$ and AOD. Then, we study the spectral mismatch correction for 3 years (2008-2010) on the site of Palaiseau (France, $48.7^{\circ} \mathrm{N}, 2.2^{\circ} \mathrm{E}, 156 \mathrm{~m}$ ) for $2 \mathrm{PV}$ technologies (crystalline Silicon (c-Si) and thin film Silicon (a-Si:H)). For comparison, the same exercise is made for Blida (Algeria, $36^{\circ} \mathrm{N}, 2^{\circ} \mathrm{E}, 230 \mathrm{~m}$ ) during one year (2009). Then, we present some solar spectrum measurements and derived mismatch factor $M$. The last part proposes a method, non PV technology dependant, to derive $M$ from atmospheric data.

\section{Tools for studying the solar spectral distribution}

In this part, we present first, a mathematical index, the average photon energy $(A P E)$, calculated to quantify the amount of energy available in the solar spectrum. Then, to take into account the spectral response of the PV cell, we define the spectral mismatch correction in $I_{s c}(M)$. Next, the modelization of the solar spectrum is described, based on the SMARTS model. We need geographical and atmospheric input parameter for this model. The AERONET atmospheric data are presented in the last paragraph of this part.

\subsection{Average photon energy}

$A P E$ has been first introduced by Betts et al. [7]. This index is defined as the sum of the light energy in the spectrum divided by the total density of the photon flux:

$$
A P E=\frac{\int_{a}^{b} E(\lambda) d \lambda}{q \int_{a}^{b} \phi(\lambda) d \lambda}
$$

$q$ is the electronic charge $(\mathrm{C}), E$ is the solar spectral irradiance ( $\mathrm{W} \mathrm{m}^{-2} \mathrm{~nm}^{-1}$ ), and $\Phi$ is the spectral photon flux density (photon $\mathrm{m}^{-2} \mathrm{~s}^{-1} \mathrm{~nm}^{-1}$ ). In this study, $a$ and $b$ are equal to $300 \mathrm{~nm}$ and $1100 \mathrm{~nm}$, respectively, corresponding to the lower and upper wavelength of the spectral response of most PV cells.
The main advantages of this tool are:

- easy indication of the "color" of the sunlight: $A P E>$ 1.895 for blue-rich sky; $A P E<1.895$ for red-rich sky; - non device-dependent indicator.

\subsection{Spectral mismatch correction}

The second tool is the spectral mismatch correction developed in equation (2):

$$
M=\frac{\int_{a}^{b} E_{\text {ref }}(\lambda) S_{\text {ref }}(\lambda) d \lambda}{\int_{a}^{b} E_{t}(\lambda) S_{\text {ref }}(\lambda) d \lambda} \frac{\int_{c}^{d} E_{t}(\lambda) S_{t}(\lambda) d \lambda}{\int_{c}^{d} E_{r e f}(\lambda) S_{t}(\lambda) d \lambda}
$$

where $E_{t}$ and $E_{\text {ref }}$ are the test and reference spectra (W $\mathrm{m}^{-2} \mathrm{~nm}^{-1}$ ), $S_{t}$ and $S_{\text {ref }}$ are the spectral response $\left(\mathrm{A} \mathrm{W}^{-1}\right)$ of the test and reference cell, $a$ and $b$, and $c$ and $d$, are the wavelength limits $(\mathrm{nm})$ of the spectral response of the reference cell and of the test cell, respectively. In this study, an ideal pyranometer is considered as reference, with a flat response over the entire solar spectrum, that is to say that $S_{\text {ref }}=1$.

Moreover, we can derive $I_{s c}$ by convoluting the spectral response of the PV cell with the incident solar spectrum, using the following equation:

$$
I_{s c}=A \int_{0}^{\lambda\left(E_{g}\right)} S(\lambda) E(\lambda) d \lambda
$$

where $I_{s c}$ is the short-circuit current (A), $A$ the cell area $\left(\mathrm{m}^{2}\right), S(\lambda)$ the spectral response of the PV cell $\left(\mathrm{A} \mathrm{W}^{-1}\right)$, $E(\lambda)$ the irradiance $\left(\mathrm{W} \mathrm{m}^{-2} \mathrm{~nm}^{-1}\right), \lambda$ the wavelength $(\mathrm{nm})$ and $E_{g}$ the band gap energy $(\mathrm{eV})$ of the PV cell.

In our study, equation (2) becomes:

$$
M=\frac{E(\mathrm{AM} 1.5)}{E(t)} \times \frac{I_{s c}(t)}{I_{s c}(\mathrm{AM} 1.5)}
$$

where $E(\mathrm{AM} 1.5)$ and $E(t)$ are the irradiation of the reference spectrum and test spectrum, between $300 \mathrm{~nm}$ and $1100 \mathrm{~nm}$, respectively. $I_{s c}(\mathrm{AM} 1.5)$ and $I_{s c}(t)$ are the short-circuit current for the considered PV cell for the AM1.5 spectrum and for the test spectrum, respectively.

The spectral mismatch correction adjusts the $I_{s c}$ of a $\mathrm{PV}$ cell, for a given spectrum, from the rated $I_{s c}$ measured under STC.

This tool is device dependent, which means that the spectral response of the PV cell must be known.

\subsection{SMARTS solar spectrum model}

The FORTRAN code "simple model for atmospheric transmission of sunshine" (SMARTS) [8-12] is the program used to model the solar spectrum under clear sky conditions by injecting atmospheric and geographic input parameter. It covers the whole wavelengths range of the solar spectrum (280 $\mathrm{nm}$ to $4000 \mathrm{~nm}$ ). It is the program used by the American Society for Testing and Materials 
T. Mambrini et al.: Photovoltaic yield: correction method for the mismatch between the solar spectrum...

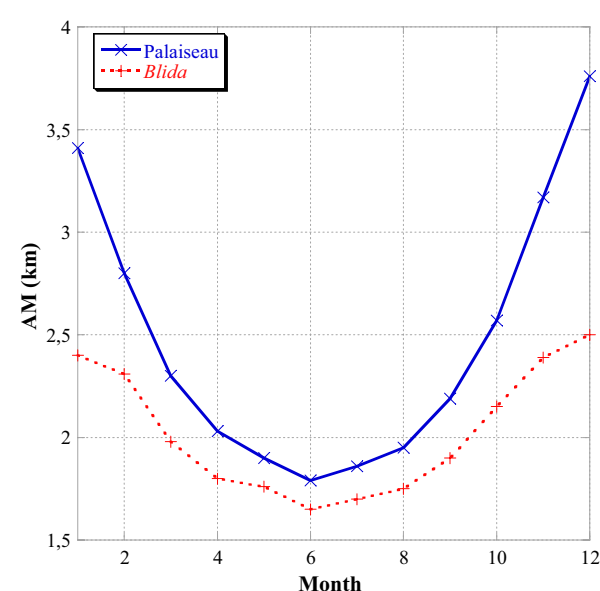

(a)

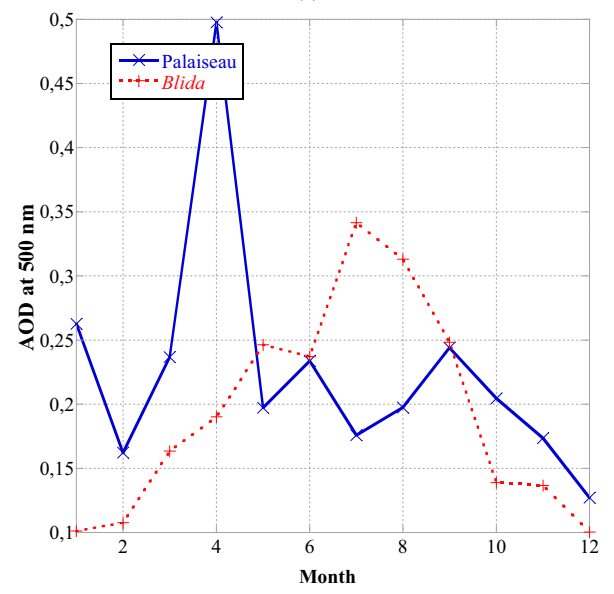

(c)

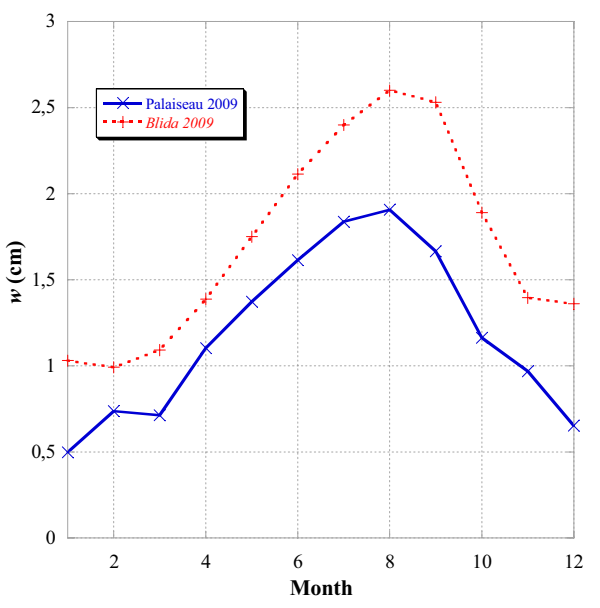

(b)

Fig. 1. Monthly average calculated $A M(\mathrm{a}), w(\mathrm{~b})$ and AOD at $500 \mathrm{~nm}$ (c) derived from AERONET data for Palaiseau and Blida during 2009.

(ASTM) to model the reference solar spectrum AM1.5, ASTM G 173-03 [2]. This model is based on parameterizations of transmittance and absorption function for atmospheric constituents include molecular (Rayleigh), ozone, water vapor, mixed gases, trace gases and aerosol transmittances.

\subsection{Atmospheric data of AERONET}

Sun photometer measurement-derived parameters from the AERONET database are considered in this study as input to the model. In particular we consider:

- aerosol optical depth (AOD) at $500 \mathrm{~nm}$;

- angstrom's alpha parameter for two wavelength intervals $(380-500 \mathrm{~nm}$ and $500-870 \mathrm{~nm})$;

- integrated water vapor $(w)$.

The single scattering albedo and the asymmetry parameters are set constant to 0.9 and 0.7 in the model, respectively, as typical values for a semi-rural site [13].

These data are entered into the SMARTS model to recover the solar spectrum distribution at a given time and for a considered site. Moreover, the $A M$ must be calculated from the zenith angle derived from the solar equation.

In this paper, only less than $78.5^{\circ}$ zenith angles are considered, leading to $A M$ under 5 . In one hand, the equation used to calculate $A M[14]$ is not accurate and, on the other hand, the solar irradiation is low and not relevant for PV applications.

Figure 1 shows monthly averaged $A M$, AOD at $500 \mathrm{~nm}$ and $w$ values (for 2009) for the two considered sites, Palaiseau and Blida.

Those geographic and atmospheric data have a great influence on the solar spectral distribution.

\section{Influence of atmospheric conditions on the solar spectrum simulated with SMARTS}

The parameters that affect the most the solar spectrum are the path length through the atmosphere $(A M)$, the amount of water vapor $(w)$ and aerosols (AOD) [15]. To evaluate their impacts, we model with the SMARTS 

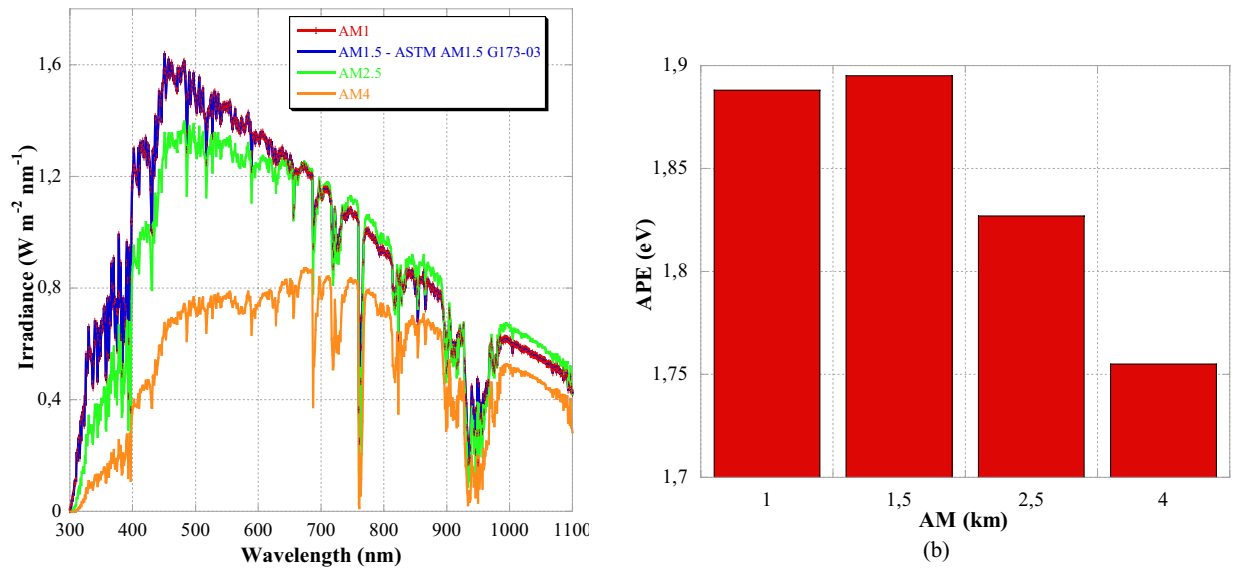

(a)
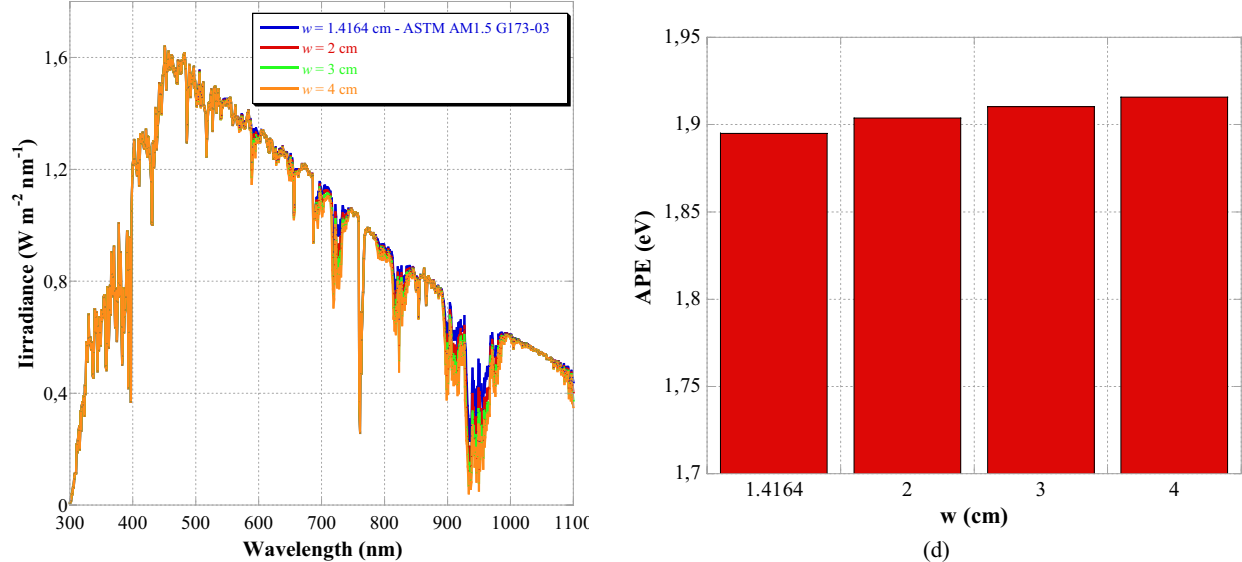

(c)
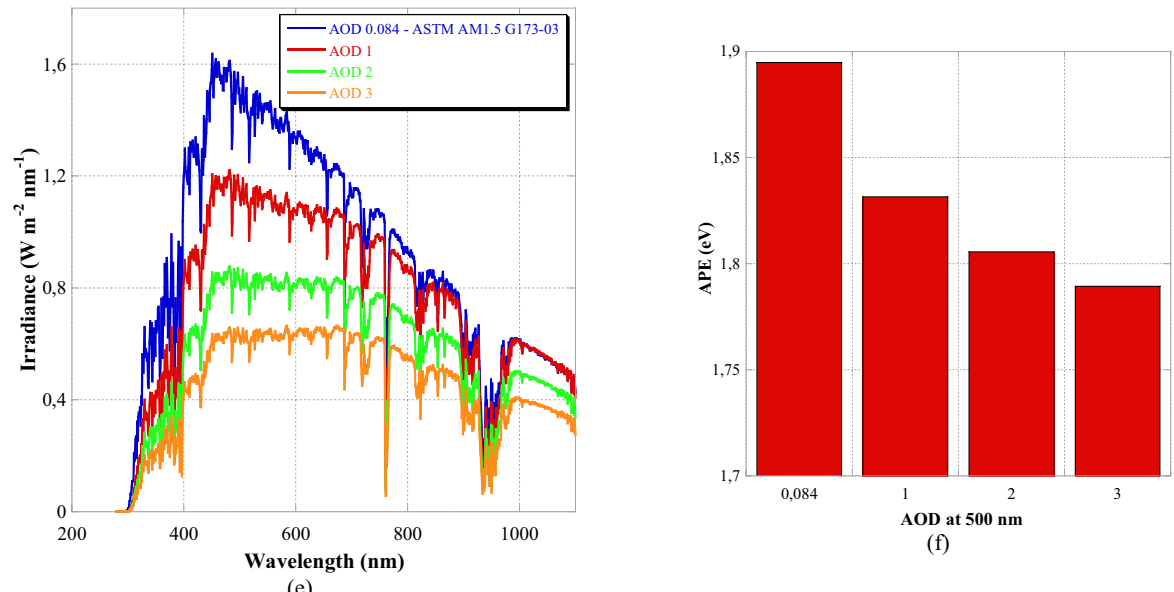

Fig. 2. Simulated spectra for different $A M$ (a), different precipitable water vapor (c) and different AOD at $500 \mathrm{~nm}$ (e). Calculated $A P E$ associated with the spectra, for different $A M(\mathrm{~b})$, different precipitable water vapor (d) and different AOD at $500 \mathrm{~nm}(\mathrm{f})$.

program, the solar spectrum with the same inputs as the ASTM AM1.5 G173-03 hemispherical spectrum excepting one parameter, such as $A M$, water vapor or aerosols. Default values are $A M=1.5 \mathrm{~km}$ and $w=1.4164 \mathrm{~cm}$ and $\mathrm{AOD}=0.084$.

The spectral range considered begins at $300 \mathrm{~nm}$ and ends at $1100 \mathrm{~nm}$ because of the spectral response of all PV cells.
Figures $2 \mathrm{a}$ and $2 \mathrm{~b}$ represent the variations of the simulated solar spectrum and the calculated $A P E$, for $A M$ varying from 1 to 4 . Figures $2 \mathrm{c}$ and $2 \mathrm{~d}$ are the same but for $w$ varying from $1 \mathrm{~cm}$ to $4 \mathrm{~cm}$. At last, Figures $2 \mathrm{e}$ and $2 \mathrm{f}$ consider the variation of AOD at $500 \mathrm{~nm}$ between 0.084 to 3 . The AOD variation is mainly due to the pollution as the pollution peak observed at Palaiseau during March 2014 which leaded to a 0.8 AOD value or during major 
T. Mambrini et al.: Photovoltaic yield: correction method for the mismatch between the solar spectrum...

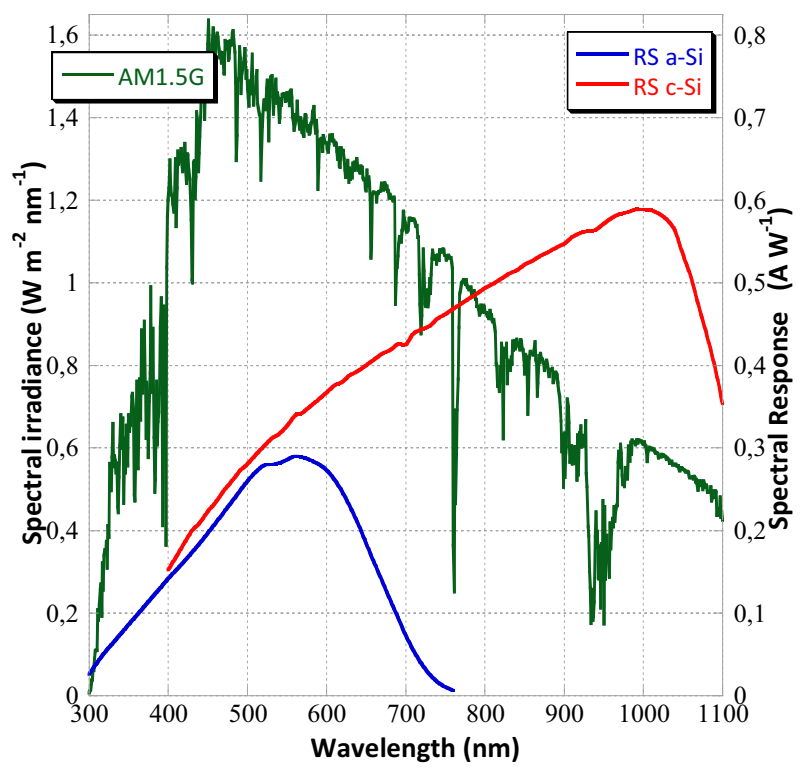

Fig. 3. Reference ASTM AM1.5G spectrum (left axis) and spectral response of a crystalline Silicon PV cell and of a thin film Silicon PV cell (right axis).

short-term pollution events as the wildfire during summer 2010 at Moscow which leaded to a 4.3 AOD value [16].

In Figure 2a, we observe that changing the path length modifies the solar spectrum intensity and distribution and in Figure 2b, we can notice that when $A M$ increases, $A P E$ decreases. That means that the more the path length through the atmosphere is long (the sun is low in the sky, for example in early in the morning or late in the evening), the more the sunlight is red-rich. It is understandable because when the path length is thick, it is the short wavelengths that are scattered.

Water vapor absorption bands are centered at $724 \mathrm{~nm}$, $824 \mathrm{~nm}$ and $938 \mathrm{~nm}$, in the considered wavelength range as one can see in Figure 2c. Figure 2d shows that when the water vapor increases, the $A P E$ increases too.

To take into account the turbidity of the atmosphere, the spectral effects of changing AOD at $500 \mathrm{~nm}$ are plotted in Figures 2e and 2f. It can be studied as the main parameter to explain the radiative extinction by aerosols. However, the aerosols spectral effects depend also on the properties of the aerosols, such as the particle size and absorption properties. Increasing AOD have the impact of solar irradiance decreasing with larger impact for shorter wavelengths, so APE decreases. Choosing on other particle size or type also has an effect on the solar spectrum.

Taking into account the variation of the solar spectral distribution is of the most important in prediction of the photovoltaic yield because of the spectral response proper to each technology of PV cell like underscored in Figure 3.

Figure 3 shows that the spectral response for the amorphous cell is more selective than that of the crystalline cell. A change in the solar spectrum acts then differently respect to the cell technology because of its spectral response.

\section{Calculating method for the spectral mismatch correction $(\mathrm{M})$ during one year, for a given site}

\subsection{Modeling the solar spectrum}

The SIRTA Atmospheric Research Observatory (www. sirta.fr), located at Palaiseau (France: $48.8^{\circ} \mathrm{N}, 2^{\circ} \mathrm{E}, 156 \mathrm{~m}$ ) has an AERONET station. The idea of this work is to calculate the spectral mismatch correction during one year for crystalline Silicon PV cells and thin film Silicon PV cells. We take monthly mean values of atmospheric conditions (AOD, $w$, size of the aerosols below and above $500 \mathrm{~nm}$ ) and monthly mean values of $A M$. In other words, we model a typical spectrum for each month of the year, for the site of Polytechnique and we derive $M$ as a function of the spectral response of the considered PV cell.

The results of this study are presented in Figure 4.

From Figure 4a, we can notice that for the thin film Silicon PV cell, there may be a difference of $9.7 \%$ between $I_{s c}$ predicted during the winter and during the summer months. $I_{s c}$ is close to its rated value during summer months and lower for winter months. In summer, $A M$ decreases and $w$ increases, as shown in Figure 3 where we can see that $w$ is four times higher in summer than in winter. This leads, in summer, to a more blue-rich solar spectrum $(A P E>1.895$ as shown in Fig. 4c), which is better suitable to the thin film PV cell spectral response (maximum absorbance around $550 \mathrm{~nm}$ ). Whereas in winter the sun is lower in the sky and $A M$ increases, which leads to a more red-rich sky $(A P E<1.895$ as shown in Fig. 4c).

The opposite effect occurs for crystalline Silicon PV cells that absorb also in the near infrared. Moreover, we can see in Figure 3 that there are two important water bands of absorption close to crystalline Silicon PV cells maximum of absorption (900-1000 nm). This means that increasing $w$ in summer has a strong effect on crystalline Silicon PV cells yield. In Figure 4b, we observe a difference due to the season of $6.6 \%$ for crystalline Silicon PV cells. They are less sensitive to the solar spectrum distribution than the thin film PV cells because of their wide spectral response [17].

On the 3 studied years in Palaiseau, the reference solar distribution spectrum overestimated $I_{s c}$ of a thin film Silicon PV cell of about $3.5 \%$ and underestimated that of a crystalline Silicon PV cell of about $2.4 \%$.

In Figure 5, the equivalent exercise is presented, for the site of Blida (Algeria: $36^{\circ} \mathrm{N}, 2^{\circ} \mathrm{E}, 230 \mathrm{~m}$ ) in 2009 .

For the Blida site, the average $A P E$ is $1.876 \mathrm{eV}$, the average $M$ for thin film Silicon PV cells is 0.985 and the average $M$ for crystalline Silicon PV cells is 1.011 during 2009. Compared to the first studied site Palaiseau, $w$ is higher and $A M$ is lower as resumed in Table 1. This leads to a more blue-rich sky for Blida than Palaiseau. We can say that, with respect to the spectral response point of view, crystalline Silicon PV cells are more efficient for high latitude site compared to thin film PV cells. 


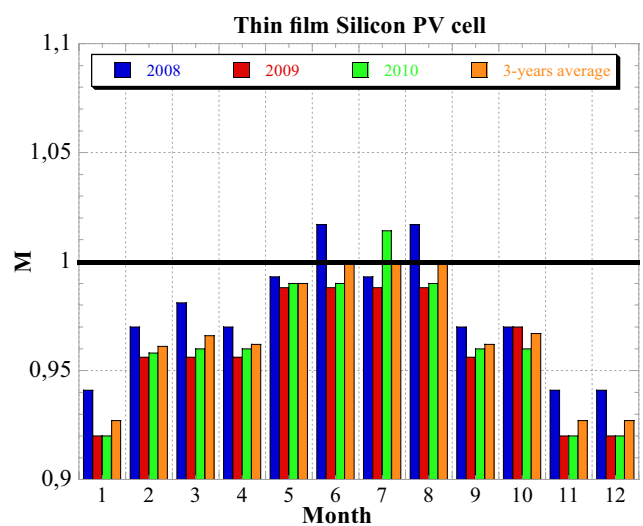

(a)

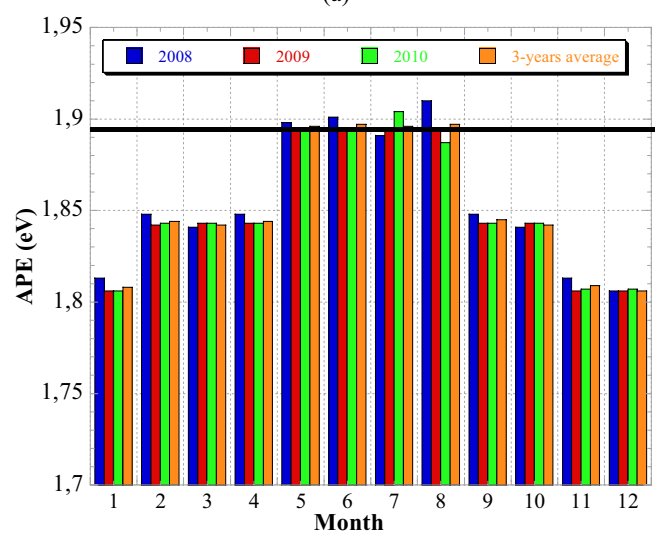

(c)

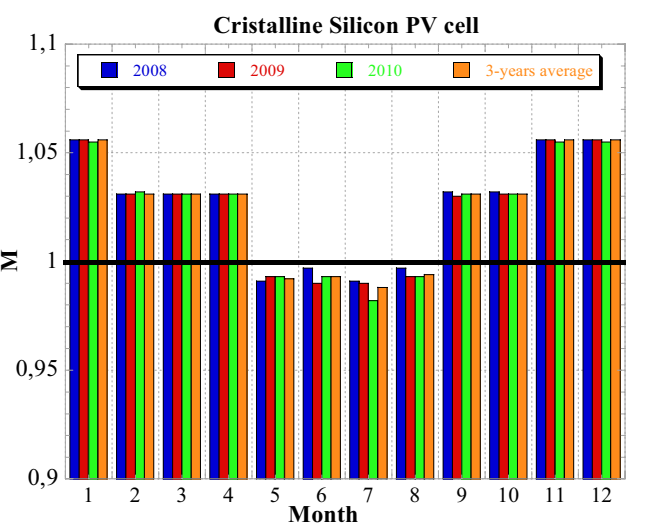

(b)

Fig. 4. $M$ calculated for thin film Silicon PV cell (a) and crystalline Silicon PV cell (b) and $A P E$ (c) corresponding to the modeled solar spectrum. All the calculated values used monthly mean atmospheric data for years between 2008 and 2010 , at Polytechnique (Palaiseau, France: $48.8^{\circ} \mathrm{N}, 2^{\circ} \mathrm{E}, 156 \mathrm{~m}$ ).

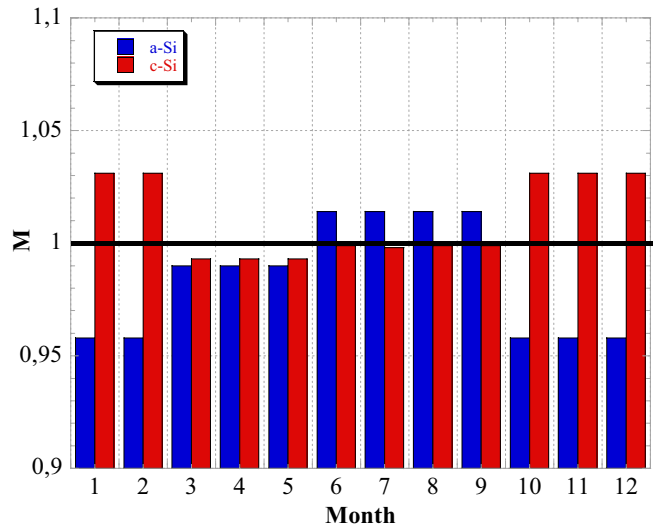

(a)

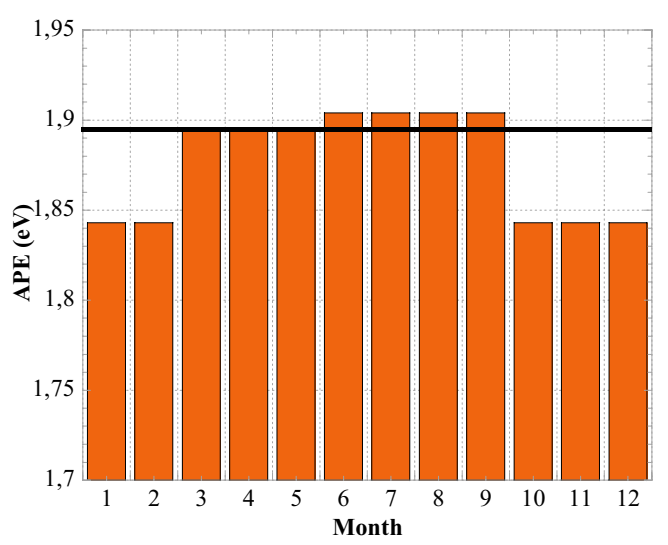

(b)

Fig. 5. $M$ calculated for thin film and crystalline Silicon PVs cell (a) and $A P E$ (b) corresponding to the modeled solar spectrum. All the calculated values used monthly mean atmospheric data 2009 , at Blida (Algeria: $48.8^{\circ} \mathrm{N}, 2^{\circ} \mathrm{E}, 230 \mathrm{~m}$ ).

Table 1. Average AM, w and APE for Palaiseau, Blida and ASTM AM1.5 G173-03 in 2009.

\begin{tabular}{|c|c|c|c|c|c|c|c|c|c|}
\hline \multirow{2}{*}{ Site } & \multirow{2}{*}{$\begin{array}{c}A M(\mathrm{~km}) \\
\text { Moy. }\end{array}$} & \multirow{2}{*}{$\begin{array}{c}w(\mathrm{~cm}) \\
\text { Moy. }\end{array}$} & \multirow{2}{*}{$\begin{array}{c}A P E(\mathrm{eV}) \\
\text { Moy. }\end{array}$} & \multicolumn{3}{|c|}{$M($ thin film $)$} & \multicolumn{3}{|c|}{$M$ (crystalline) } \\
\hline & & & & Min. & Max. & Moy. & Min. & Max. & Moy. \\
\hline Palaiseau & 2.478 & 1.246 & 1.852 & 0.920 & 0.988 & 0.959 & 0.990 & 1.056 & 1.024 \\
\hline Blida & 2.024 & 1.712 & 1.876 & 0.958 & 1.014 & 0.985 & 0.993 & 1.031 & 1.011 \\
\hline ASTM AM1.5 & 1.5 & 1.416 & 1.895 & & & 1 & & & 1 \\
\hline
\end{tabular}


T. Mambrini et al.: Photovoltaic yield: correction method for the mismatch between the solar spectrum...

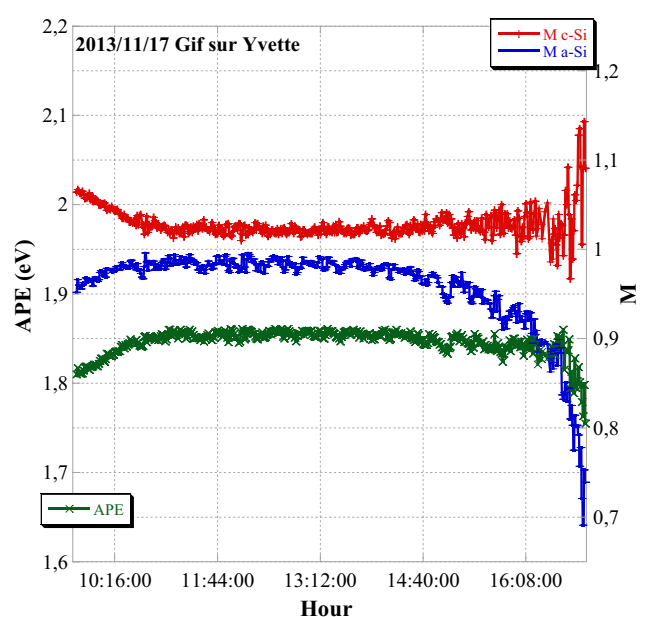

(a)

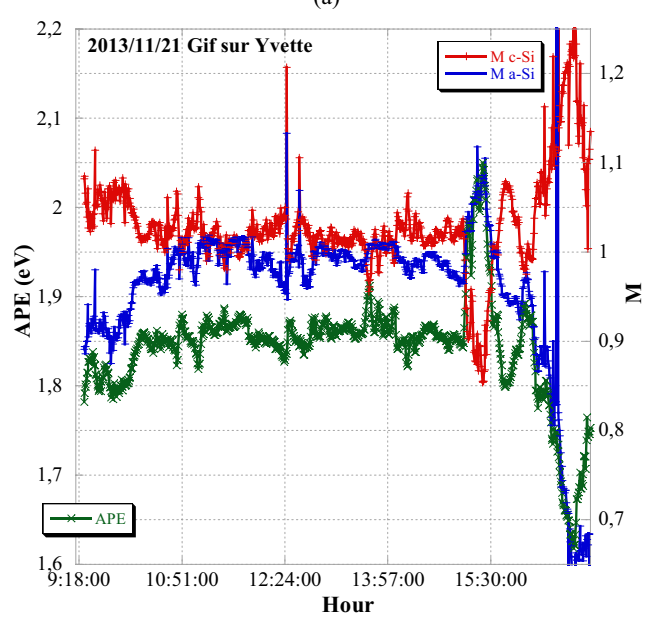

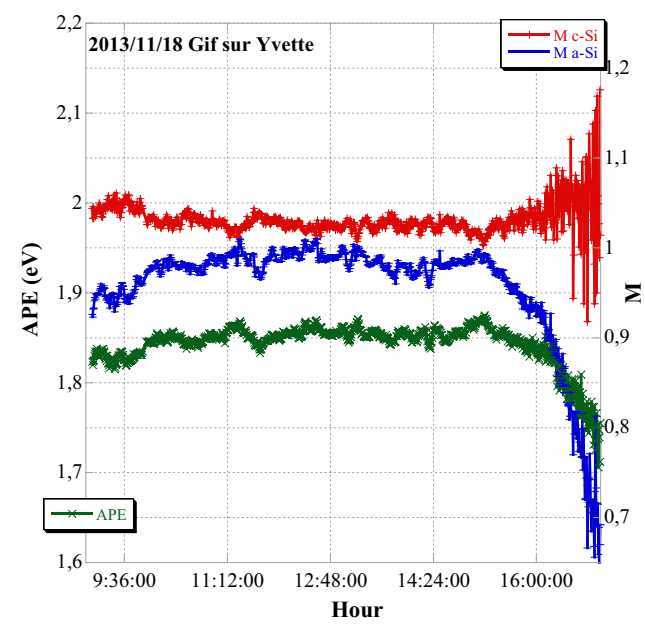

(b)

(c)

Fig. 6. Calculated $A P E$ and $M$ during three days at LGEP, Gif-sur-Yvette (near Palaiseau), 2013/11/17 (a), 2013/11/18 (b) and $2013 / 11 / 21$ (c).

\subsection{Measuring the solar spectrum}

Another way, more accurate, to estimate the spectral mismatch correction is to measure the solar spectrum with a USB2000+ Spectrometer with Enhanced Sensitivity (from 210 to $1035 \mathrm{~nm}$ ) produced by Ocean Optic. Measures of the solar spectrum are taken every $30 \mathrm{~s}$ from the sunrise to the sunset and we derived, in Figure 6, the values of $A P E$ and $M$ for crystalline Silicon PV cells and thin film Silicon PV cells. We can observe that at the beginning and the end of the day, thin film Silicon PV cell has a lower $M$ contrary to the crystalline Silicon PV cell. This can be mainly explained by the fact that the $A M$ is higher during these periods and then the spectrum is less blue-rich. This is confirmed by looking at the $A P E$ which is higher around noon than at the beginning or at the end of the day.

One goal of that kind of study would be to make more accurate models used for PV plant production. For instance, the very used PVsyst software or the Sandia model, utilize an empirical function $f_{1}\left(A M_{a}\right)$ to quantify the influence of variation in the solar spectrum, on the short-circuit current of the PV module [18]:

$$
\begin{aligned}
I_{s c}= & I_{s c 0} \times f_{1}\left(A M_{a}\right) \times f_{E}(\mathrm{AOI}) \times f_{T}(T) \\
f_{1}\left(A M_{a}\right)= & a_{0}+a_{1} A M_{a}+a_{2}\left(A M_{a}\right)^{2} \\
& +a_{3}\left(A M_{a}\right)^{3}+a_{4}\left(A M_{a}\right)^{4} .
\end{aligned}
$$

$f_{1}$ is a 4th order polynomial function of absolute air mass $A M_{a}$, and is called the air mass modifier, where $a$ is a vector of coefficients that are determined from module testing.

If we model or measure $M$ during one year in one site, then substitute $f_{1}\left(A M_{a}\right)$ by the measured $M$ in these programs should reduce uncertainty respect to the solar spectrum.

\section{Conclusion}

The solar spectrum variations differently impact the short-circuit current of solar cells, according to their technology. A spectral mismatch correction $(M)$ must be applied to $I_{s c}$ estimated under reference spectral conditions 
(ASTM G 173-03) to evaluate precisely the yield of a PV module, for a given site.

This paper gives a method to calculate the spectral mismatch correction according to a PV cell, in a given site. The needed information to take into account is the AERONET monthly data or the solar spectrum measured by a spectrometer. Thus, we can derive the $A P E$ and $M$, and the associated $I_{s c}$. This can be particularly useful for decrease the uncertainty in $\mathrm{PV}$ plant prediction models like PVsyst or the Sandia model.

Application for the site of Polytechnique (Palaiseau) in France, is realized using data issued from the SIRTA during 3 years (2008-2010). We found a difference of $9.7 \%$ for $I_{s c}$, throughout one year for thin film Silicon PV cells and $6.6 \%$ for crystalline Silicon PV cells. That highlights the importance to consider the spectral mismatch correction. For comparison, we made the same study in the site of Blida in Algeria.

We also emphasize that the reference AM1.5 solar spectrum is blue-rich respect to the mostly real solar spectrum for high latitudes.

The authors acknowledge the support from ADEME project POLYSIL and from the collaboration with the JEI SOLEÏS Technologie, France.

\section{References}

1. IEC 60904-3, Photovoltaic devices-Part 3: Measurement principals for terrestrial photovoltaic $(P V)$ solar devices with reference spectral irradiance data (2008)

2. American Society for Testing and Materials, ASTM G 173-03, Standard Tables for Reference Solar Spectral Irradiances: Direct Normal and Hemispherical for $3{ }^{\text {ro }}$ Tilted Surface (American Society for Testing and Materials, West Conshohocken, 2003)

3. K. Akhmad, A. Kitamura, F. Yamamoto, H. Okamoto, H. Takakura, Y. Hamakawa, Sol. Energy Mater. Sol. Cells 46, 209 (1997)
4. T. Minemoto, M. Toda, S. Nagae, M. Gotoh, A. Nakajima, K. Yamamoto, H. Takakura, Y. Hamakawa, Sol. Energy Mater. Sol. Cells 91, 120 (2007)

5. A. Mermoud, T. Lejeune, Performance assessment of a simulation model for PV modules of any available technology, 25th European Photovoltaic Solar Energy Conference, Valencia, Spain (2010)

6. B.N. Holben et al., Rem. Sensing Environ. 66.1, 1 (1998), http://aeronet.gsfc.nasa.gov/new_web/system_ descriptions.html.

7. T.R. Betts, C.N. Jardine, R. Gottschalg, D.G. Infield, K. Lane, 3rd World Conference on Photovoltaic energy Conversion, Osaka, 2003

8. C. Gueymard, Development and performance assessment of a clear sky spectral radiation model, Solar'93-22nd Annual Conf., American Solar Energy Society, Boulder, Washington, 1993

9. C. Gueymard, Updated transmittance functions for use in fast spectral direct beam irradiance models, in Solar '94 Conf., American Solar Energy Society, Boulder, San Jose, 1994

10. C. Gueymard, SMARTS2, Simple model of the atmospheric radiative transfer of sunshine: Algorithms and performance assessment, Rep.FSEC-PF-270-95 (Florida Solar Energy Center, Cocoa, 1995)

11. C. Gueymard, Sol. Energy 71, 325 (2001)

12. C. Gueymard, D. Myers, K. Emery, Sol. Energy 73, 443 (2002)

13. M. Iqbal, An introduction to solar radiation (Elsevier, 1983)

14. F. Kasten, A.T. Young, Appl. Opt. 28, 4735 (1989)

15. G. Litjens, Investigation of Spectral Effects on Photovoltaic Technologies by Modelling the Solar Spectral Distribution (Universiteit Utrecht, 2013)

16. A. Donkelaar, R.V. Martin, R.C. Levy, A.M. Da Silva, M. Krzyzanowski, N.E. Chubarova, E. Semutnikova, A.J. Cohen, Atmospheric Environment 45, 6225 (2011)

17. D.L. King, W.E. Boyson, J.A. Kratochvil, Photovoltaic Array Performance Model (Sandia National Laboratories, Albuquerque, 2004)

18. Y. Hirata, T. Tani, Sol. Energy 55, 463 (1995) 